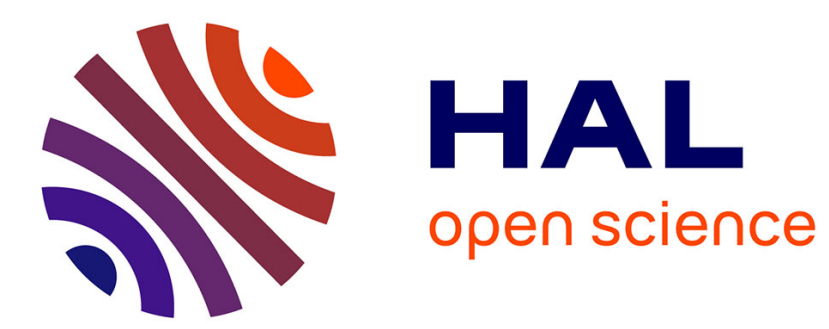

\title{
Improving the robustness of a supply chain tactical plan
}

Patrick Genin, Samir Lamouri, André Thomas

\section{To cite this version:}

Patrick Genin, Samir Lamouri, André Thomas. Improving the robustness of a supply chain tactical plan. Supply Chain Forum: An International Journal, 2007, 8 (2). hal-00121363

\section{HAL Id: hal-00121363 \\ https://hal.science/hal-00121363}

Submitted on 20 Dec 2006

HAL is a multi-disciplinary open access archive for the deposit and dissemination of scientific research documents, whether they are published or not. The documents may come from teaching and research institutions in France or abroad, or from public or private research centers.
L'archive ouverte pluridisciplinaire HAL, est destinée au dépôt et à la diffusion de documents scientifiques de niveau recherche, publiés ou non, émanant des établissements d'enseignement et de recherche français ou étrangers, des laboratoires publics ou privés. 


\title{
Improving the robustness of a supply chain tactical plan
}

Patrick Genin ${ }^{\text {a }}$, Samir Lamouri ${ }^{\mathrm{a}, *}$, André Thomas ${ }^{\mathrm{b}}$

${ }^{a}$ SUPMECA Paris, LISMMA, 3 rue Fernand Hainaut, 93407 St OUEN Cedex, France

${ }^{\mathrm{b}}$ CRAN, Faculté des sciences, BP239, 54506, Vandœuvre les Nancy, France.

\begin{abstract}
Based on linear and linear integer programming techniques, Advanced Planning Systems (APS) enable a tactical plan to be established each time the plan deviates from reality. Thus, planning is more reactive but may lead to a loss of robustness when making a decision.

This article presents a specific approach to increase robustness and stability for tactical plans. Several methods have already been discussed to achieve this robustness target. This proposed new policy is called the "reference plan".
\end{abstract}

Keywords: Robustness, Stability, Tactical planning, Advanced Planning System

\section{Introduction}

A supply chain is a network of entities which supplies material, transforms it into an intermediate and then finished product, and distributes the finished products to the customers (Lee and Billington, 1995). Historically, these three activities were managed independently. The complex links of the supply chain were ignored (Thomas and Griffin, 1996). Supply Chain Management (SCM) arose in this context in order to ensure the management of both material and data flows at the same time, within and between those entities, so as to synchronize their activities (Christopher, 1992).

Distribution, production and procurement are operationally coordinated at the tactical planning level (Stadtler and Kilger, 2000). The levels of resources and the flows between the entities of the supply chain, etc., are determined in order to synchronize the capacities and

\footnotetext{
* Corresponding author. Tel.: +33 14945 25 46; fax: +33 1494529 91; e-mail: samir.lamouri@supmeca.fr
} 
the flows simultaneously. For this purpose, different scenarios are often evaluated by indicators aggregated in a cost function. The resulting plan defines the reasonable and feasible levels in terms of production and transfer between entities, as well as the required resource level in the supply chain for planned finished products. The plan established a compromise that minimises service costs (backlogs, non-delivery, and profitability of products), inventory levels (holding costs, additional storage capacity) and resources (costs of production, capacity, transport, subcontracting...). Hence tactical planning partially covers Sales and Operations Planning, which ensures the coordination between the various functions of the firm and determines the optimal scenario which will minimize the various expenses and maximize the sales (Vollman et al., 1997).

Advanced Planning Systems (APS) support tactical planning (Stadtler and Kilger, 2000). The technical progress made in computing power enables the calculation of a plan within a few minutes. By using these tools, management can re-optimise the model each time an event puts the current tactical plan into question. The plan is always « optimal » for all variations in the input data. Doing so, they can reach the desired reactivity while maximizing profitability, but without being concerned with modifications made in the plan. These practices induce strong disturbances on the productive system and on the partners of the supply chain by generating the bullwhip effect (Forrester, 1958). The overcosts created by these variations are not taken into account in the system global optimisation.

From another point of view, the calculation of tactical plans by commercial software is based on linear and linear integer programming optimisation techniques (Stadtler and Kilger, 2000). These calculations are relatively well adapted to the problem at hand (Johnson and Montgomery, 1974), (Yu and Li, 2000), as long as we assume a linear 
relationship between cost and volume. Yet, these techniques are known for determining optima which are sensitive to fluctuations of the parameters or the costs of the model. The above-mentioned method, consisting of re-optimising the model when an event influences its parameters, leads to reactive but non-robust planning.

Sensitivity analysis is the main approach used to evaluate the effects of changes in the coefficients of the objective function (the costs) and in the members of the constraints vector (the constraints), as well as the range of validity of these effects (Koltai and Terlaky, 2000). It determines the value of the parameters of the model for which a given solution remains optimal. However, this sensitivity analysis studies the impact of independent variations of different parameters. It doesn't enable the manager to study sub-optimal solutions which are less sensitive to simultaneous fluctuations of the factors and are, therefore, more robust.

When the system is subjected to the effects of "noncontrollable" factors, Taguchi (1987) recommends the use of cross-designed orthogonal plans. Thomas and Lamouri (2000) used Taguchi's method to analyse the impact of uncontrollable factors on a tactical plan cost calculated by linear optimisation. They demonstrate that robust optimal solutions could be found using this technique. They determine the strategies, i.e. the decisions to be made, for a better plan robustness on the cost function by choosing the set of controllable parameters minimizing the "quality loss" function. They show that it is possible to find a robust tactical plan. However the time of implementing such an experimental design (even fractional) is limited for industrial use.

In this paper, we propose to study how the process used to elaborate the tactical plan influences its robustness. In doing so, we compare two different processes changing only the 
policy used. We highlight the effects of each one on several indicators. For the purposes of our study, the next section defines the terms of robustness and stability. In section 3, we describe the linear model used to compare the two policies. Section 4 presents an iterative method which simulates the elaborating processes. The results of the simulation will be presented in section 5. Section 6 will deal with our conclusions and prospects.

\section{Underlying concepts of robustness and stability}

In a supply chain, uncertainty appears through demand (volume and mix), process (yield, scrap...) and procurement (quality and reliability of the delivery lead times). Inventories or buffers generally compensate it. Other researchers have shown that the structure of the supply chain itself may generate fluctuations (Simchi-Levi et al., 2000). Indeed, a decision concerning an industrial activity generally causes adjustment decisions for other activities. The effects of the first decision tend to reduce quickly with time, but the combination of the following decisions taken by the same or other associates influence the system overall. The complexity of managing the supply chain due to all the variations was highlighted by the phenomenon usually called the "bullwhip effect" which is an amplification effect (Forrester, 1958). The solution proposed is a better synchronisation amongst the entities and is supported by cooperation and reinforced communication between the entities of the logistic network (Simchi-Levi et al., 2000). However, the compromises have to go behind divergent targets (inventory availability, costs...). Moreover, Holmström (1997) shows that these effects amplify as companies cooperate more.

In such a fluctuating and uncertain context where the terms robustness and stability are used, the definition of these words proves to be necessary.

\section{a) Stability}

The term stability is generally associated, by opposition, with that of nervousness: De Kok 
and Inderfurth (1997) have defined "nervousness" as "a lack of stability in the material requirements planning”.

Planning nervousness is often treated in the literature at the MRP level (Yano and Carlson, 1987), (Minifie and Davis, 1990), (Sridharan and Laforge, 1990), (Kadipasaoglu and Sridharan, 1995), (Blackburn et al. 1986), (Ho, 1989), (Jensen, 1993), (Heisig, 1998).

Several authors have explained MRP systems' nervousness (Orlicky, 1975) and the difficulties induced by "schedule nervousness caused by uncertainty in demand or supply or by dynamic lot-sizing that can be an obstacle to effective execution of material requirements planning systems" (Kadipasaoglu and Sridharan, 1995). Several strategies to dampen nervousness or to increase planning stability in MRP systems were proposed:

- to lengthen the planning horizon (Carlson et al. 1982), to freeze the Master Production Schedule within this planning horizon (Zhao and Lee, 1993) and to position buffers (Blackburn et al. 1986),

- to distinguish between small and large changes (Ho, 1989).

In their article, De Kok and Inderfurth (1997) study the stability of the plan in volume. They use, as did Kimms (1998), the expected value of variation in the quantities between two periods in the planning. Donselaar et al. (2000) study the stability of the plan in buckets. They compare the nervousness of the plan generated by MRP with that of their heuristics. The indicator considered is the number of "re-plannings" encountered. The instability studied is the change within the periods. If a quantity appears or disappears in a time bucket, the indicator is incremented. However, if quantities are only modified, the indicator does not change. 
The instability of a plan is often defined by the number of modifications made on the decision variables of the model between two successive versions of the plan. The term stability is related to the decision variables. In MRP context, it is the quantity by bucket to be produced or supplied.

\section{b) Robustness}

The term robustness is associated with that of risk and decision-making (Kleijnen and Gaury, 2003). The underlying idea of system robustness is that the measured function does not diverge significantly from a given value. A system is known as robust if it provides a weak dispersion of the target performances in spite of the variations of the non-controllable factors. The robustness relates to the dispersion of several functions subject to uncertain parameters and costs (Lee and $\mathrm{Yu}, 1997)$. Kleijnen and Gaury (2003) studied the robustness of a kanban loop according to two functions: average wip in the loop and the delivery performance.

\section{c) Robustness and stability approaches}

Thus, a system can give a robust answer, i.e. a weak dispersion of the cost function, but be unstable by systematically varying the decisions variables of the system to obtain an identical cost. In the same way, a system can be stable, i.e. few variations of the variables of decisions, while not being robust since the function cost can diverge because of significant fluctuations in conditions.

Taguchi (1987) considers robustness of a function by making the hypothesis that it can be controlled by the quadratic functions "losses" or by the signal-to-noise functions which combines the mean and the variance of result. 
Frequently, APS vendors limit themselves by delivering to their customers the mathematical models that provide "optimal" plans (Stadtler and Kilger, 2000). However, the robustness of these plans is not considered. An optimal solution for a scenario is not exploitable if it becomes inefficient with a small change in parameters. It will lead to higher costs.

Linear programming requires the user to describe deterministic models. It is complex to describe the majority of concrete logistic problems containing uncertainty, "noise", and incomplete information in linear programming models (Graves et al., 1993). The traditional approach for optimising problems containing probabilistic parameters is stochastic programming. Many theoretical developments were made since the work of the pioneers Dantzig (1955) and Beale (1955). The objective of stochastic programming is to optimise the expected value of performance indicators. However, these techniques are not yet able to solve problems of realistic size at the tactical level (Mulvey and al., 1995).

Mulvey et al. (1995) proposed an approach called "robust programming", which is able to simulate the sensitivity to risk of a manager or to guarantee a level of service, to lead to a series of solutions which are gradually less sensitive to the variations of model data. They introduce penalties into the linear model so that the modifications of the decisions variables are an optimisation criterion.

\section{Our model}

\section{a) General description}

The studied supply chain delivers transportation and power systems (turbochargers) to automotive constructors. This supply chain contains one raw material plant (turbo body) 
several assembly firms and a distribution system. Thus, the company supply one raw material for each delivered product. In this context, the tactical plan is useful to define the forecasted production, inventory and workforce, essential for financial objectives.

The model describes a simplified situation of decision-making for a production level and capacity changes for a product group. The manager seeks the best compromise between service levels, inventories, and production costs related to the adjustments of capacity. At each period and for each optimisation of the basic model, all the decision variables are adjusted according to the modifications in demand. It does not take into account the decisions taken during the previous period in supplied quantities, levels of production, and the possible recruitment. It can therefore negate decisions, from one period to another, without taking into account the costs associated with these changes (generation of the model $\mathrm{P}_{\mathrm{o}} \mathrm{n}-$ figure 1).

This basic model is modified to simulate another planning process limiting the modifications made to a "reference plan". The reference plan (Figure 1) is the tactical plan validated by the concerned departments, at least production, sales, and supply chain during a meeting. It is implemented at the previous period (plan $\mathrm{P}_{\mathrm{R}} \mathrm{n}-1$ ). It is used as a framework to set up the new tactical plan of the current period $n\left(P_{R} n\right)$.

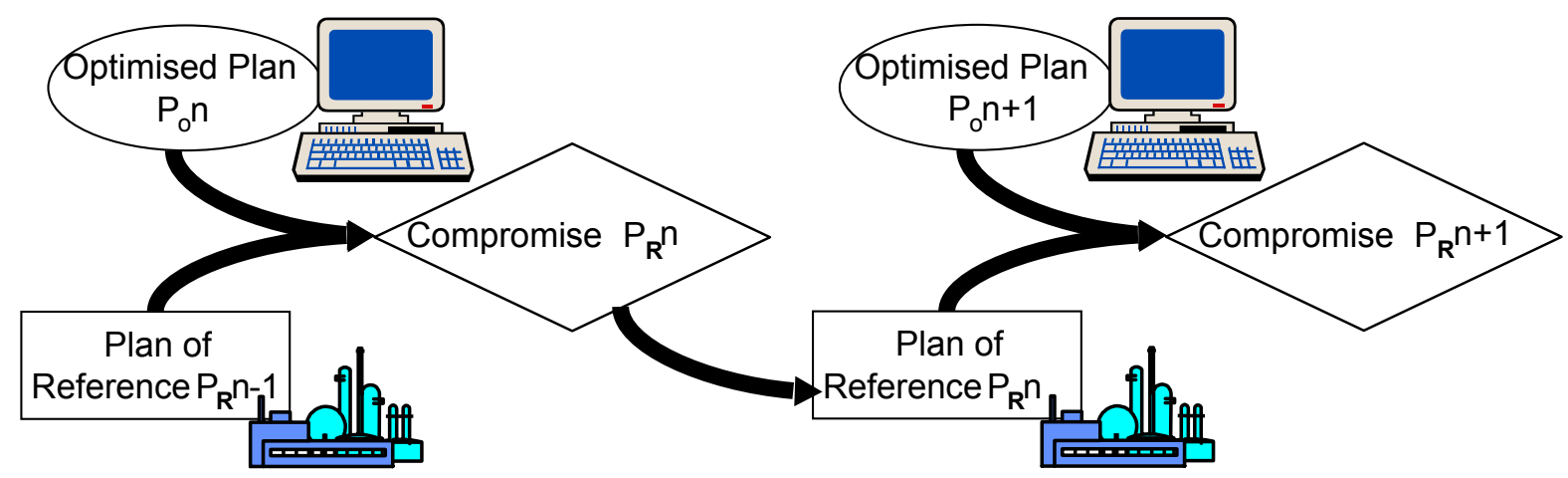


Figure 1: the reference plan

This plan remains a reference as long as the control factors influencing it have not evolved significantly, i.e. remains below a defined threshold.

In a planning policy with a "reference plan", the model takes into account the decisions made in this reference plan to find the best compromise between modification of these decisions and optimisation of an "ideal" model. Thus, the manager's reluctance to modifications of these decisions is represented by a weight on the difference between the new level of the decisions variables and those of the reference plan. The model minimises the cost generated by the variations on the decision variables compared to the reference plan, while minimising the total cost of the plan.

An alternative approach would be to optimise the model by constraining the number of modifications made to the reference plan. The term modification has then to be defined: it can be a simple variation or a variation exceeding a certain threshold defined by the manager. This last case approaches the theory of the control where there is a "dead" zone around the value of a decision variable in which no action is taken. This approach results in modifying the linear model to introduce integer variables. In this article, we used weightings to preserve a reasonable processing time for the problem.

Several decision variables can be taken into account (production quantity, overtime, employees...). In the model described below, we chose the forecasted supply quantities transmitted to the raw material plant as the decision variables to stabilise, because they correspond with one of the top priorities in tactical plans. That is why only the costs of changing raw material quantity have been introduced. 
The quality of demand forecasts strongly influences the global optimisation of the logistic processes (Lee and Billington, 1995). Disney and Towill (2003) determined how their approach of inventory control impacts the bullwhip effect in a supply chain. They measured the variations in the behaviour of the objective function of their simulation model when faced with changes in demand volume. For that, the difference between the forecast and the demand was modelled by a normal law. In another study, Rota et al. (2002) modelled the forecasted demand between a mini and maxi in opposition to firmed demands for which the expression was constant.

In our case, using the same experimental logic, uncertainty is created by forecast error. The forecasts generation is made according to the simple exponential smoothing model with a coefficient of sensitivity (fixed at 0.3 ) reflecting a variable market in order to simulate a certain nervousness. Indeed, the model of exponential smoothing (see Equation (0)) takes into account the recent past with a more significant weighting, which leads to more realistic values.

$$
\begin{aligned}
& F_{p+1}(t+1)=\alpha F_{p+1}(t)+(1-\alpha) F_{p}(t+1) \quad \forall t>p \\
& F_{p+1}(p+1)=\alpha D(p)+(1-\alpha) F_{p}(p+1) \\
& \alpha=0.3
\end{aligned}
$$

This phenomenon is also explained by Simampo and Ryan (2003) and is an assumption necessary to the specification of the context. Zhao et al. (2002) studied the impact of forecasting models on information necessary to manage the supply chain. Our purpose was to analyse the impact of a reference plan on the robustness of the tactical plan, we did not desire to vary the parameters of demand. However, in a future work, we will complete the analysis by taking into account, in an experimental design, all these parameters. 
The exponential smoothing model takes into account the recent past (the demand of past period $\mathrm{D}(\mathrm{p})$ ) with a more significant weighting, which leads to more realism in the forecasted values. However this model induces consequently more nervousness in demand (the phenomenon we want to simulate). With regard to the real demand, the normal distribution generates good variability. The forecasts established for the subsequent periods are recomputed by taking into account the real demand. Table 1 shows an example of forecast calculations for a set of real demand. The forecasts calculated for period $p$ have been used for model optimisation at period $\mathrm{p}$.

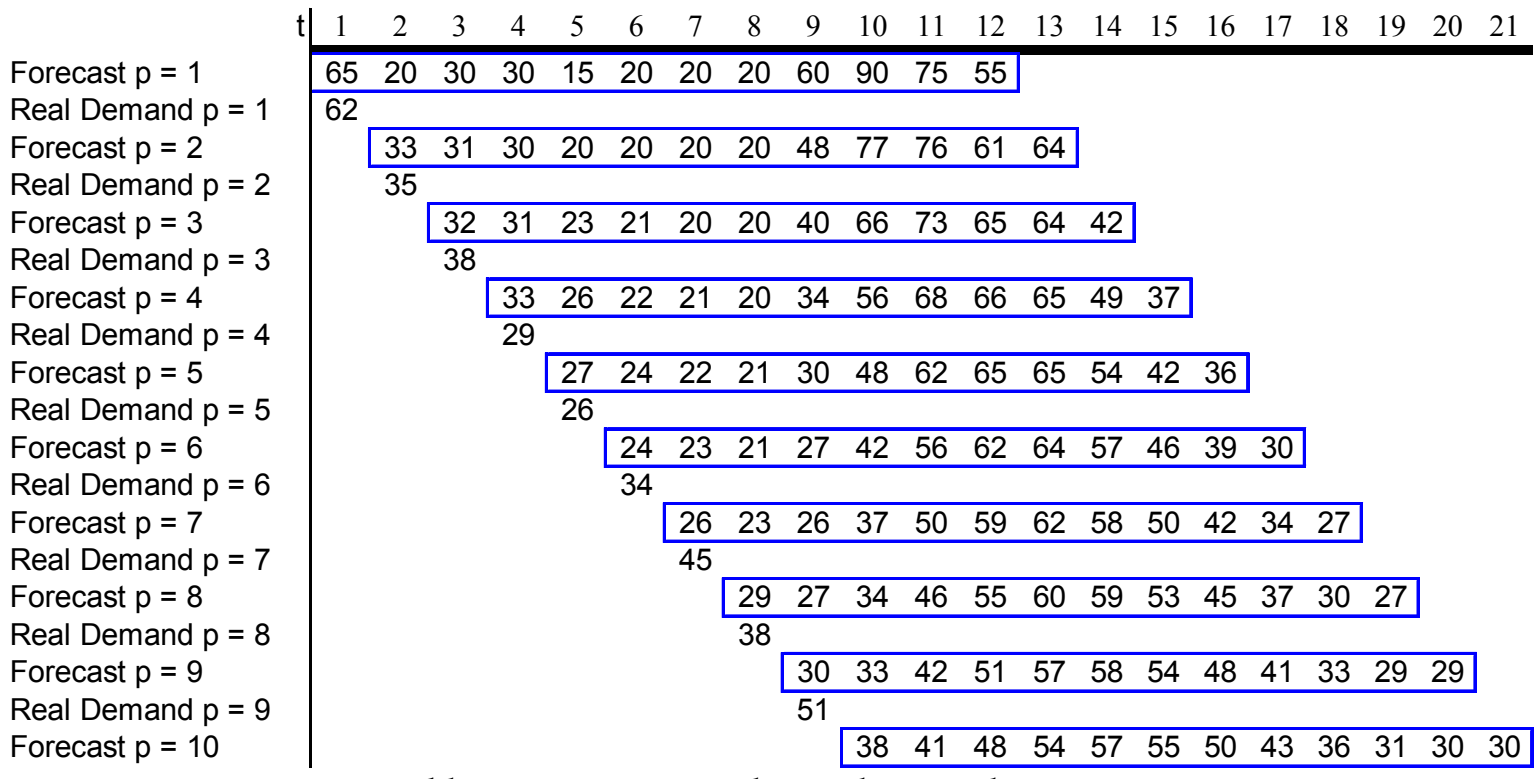

Table 1: uncertainty in demand, $\alpha=0.3$, horizon $=12$

10 '000 sets of rolling forecasts and associated real demands were generated prior to any simulation. These sets were used with both processes of elaborating tactical plan.

\section{b) Notation}

$\mathrm{n}$ : number of periods incremented during simulation,

h: horizon of the tactical plan,

$\mathrm{p}$ : the current period index of simulation $\mathrm{p}=1,2 \ldots \mathrm{n}$,

$\mathrm{t}$ : index of the period of the plan $\mathrm{t}=\mathrm{p}, \mathrm{p}+1, \ldots, \mathrm{p}+\mathrm{h}-1$,

$F_{p}(t)$ : demand forecast for period $t$ calculated in period $p$, 
$\mathrm{D}_{\mathrm{p}}$ : real demand for period $\mathrm{p}$,

$\mathrm{CR}(\mathrm{t})$ : maximum resource capacity usable in period $\mathrm{t}$ in production unit,

$\mathrm{CS}(\mathrm{t})$ : maximum storage capacity usable in period $\mathrm{t}$ in production unit, $u(t)$ : quantity of production units in period t per operator, uo(t): quantity of production units per overtime hour in period $t$, $\mathrm{CO}(\mathrm{t})$ : maximum of overtime hours per operator in period $\mathrm{t}$,

$\mathrm{I}_{0}$ : Beginning inventory (positive or null),

$\mathrm{B}_{0}$ : Beginning backorders (positive or null),

$\mathrm{IM}_{0}$ : Raw material beginning inventory (positive or null),

$\mathrm{O}_{0}$ : beginning number of operators (positive or null),

$\mathrm{I}_{\mathrm{h}}$ : target level of inventory (positive or null),

$\mathrm{R}_{\mathrm{h}}$ : target level of backorders (positive or null),

$\mathrm{O}_{\mathrm{h}}$ : target numbers of operators (positive or null),

$\mathrm{C}_{\mathrm{S}}(\mathrm{t})$ : storage cost per production unit in period $\mathrm{t}$,

$\mathrm{C}_{\mathrm{B}}(\mathrm{t})$ : cost of backorders per production unit for one period in period $\mathrm{t}$,

$\mathrm{C}_{\mathrm{H}}(\mathrm{t})$ : cost of hiring one operator in period $\mathrm{t}$,

$\mathrm{C}_{\mathrm{L}}(\mathrm{t})$ : cost of one layoff in period $\mathrm{t}$,

$\mathrm{W}(\mathrm{t})$ : wages per operator in period $\mathrm{t}$,

$\mathrm{C}_{\mathrm{O}}(\mathrm{t})$ : cost of one overtime hour in period $\mathrm{t}$,

$\mathrm{C}_{\mathrm{SU}}(\mathrm{t})$ : supply cost of one unit in period $\mathrm{t}$,

$\mathrm{C}_{\mathrm{MS}}(\mathrm{t})$ : storage cost per unit of raw material in period $\mathrm{t}$,

$\mathrm{OH}_{\mathrm{p}}(\mathrm{t})$ : numbers of overtime hours in period $\mathrm{t}$ planned in period $\mathrm{p}$,

$\mathrm{O}_{\mathrm{p}}(\mathrm{t})$ : numbers of operators in period $\mathrm{t}$ planned in period $\mathrm{p}$,

$\mathrm{H}_{\mathrm{p}}(\mathrm{t})$ : number of hired operators in period t planned in period $\mathrm{p}$,

$L_{p}(t)$ : number of layoffs in period t planned in period $p$, 
$I_{p}(t)$ : level of inventory at the end of period t planned in period $p$

$B_{p}(t)$ : level of backorders at the end of period $t$ planned in period $p$,

$\mathrm{IM}_{\mathrm{p}}(\mathrm{t})$ : level of raw material inventory at the end of period $t$ planned in period $\mathrm{p}$,

$\mathrm{P}_{\mathrm{p}}(\mathrm{t})$ : numbers of production units manufactured in period $\mathrm{t}$ planned in period $\mathrm{p}$,

$\mathrm{S}_{\mathrm{p}}(\mathrm{t})$ : numbers raw material units to be supplied in period $\mathrm{t}$ planned in period $\mathrm{p}$.

\section{c) Linear model}

The manager seeks to optimise resource use, minimising the costs over the whole horizon of his plan $\mathrm{CT}(\mathrm{p})$ at each period $\mathrm{p}$ under constraints of the equations (2)-(10).

$$
\begin{gathered}
C T(p)=\sum_{t=p}^{p+h} C_{S}(t) \times C_{p}(t)+C_{B}(t) \times B_{p}(t)+C_{H}(t) \times H_{p}(t)+C_{M S}(t) \times I_{p}(t)+C_{L}(t) \times L_{p}(t)+W(t) \times S_{p}(t)
\end{gathered}-\forall p
$$

These costs are the storage cost of finished products, the cost of backorders, the costs of hiring and layoffs, wages, overtime, storage cost and supply costs of raw materials. Equation

(1) can also be rewritten in equation ( $\left.1^{\prime}\right)$ :

$$
C T(p)=\sum_{t=p}^{p+h} C_{p}(t) \quad \forall p \quad\left(1^{\prime}\right)
$$

where $C_{p}(t)$ is the monthly cost in period $t$ of the optimised plan in period $p$ :

$$
\begin{aligned}
& C_{p}(t)=C_{S}(t) \times I_{p}(t)+C_{B}(t) \times B_{p}(t)+C_{H}(t) \times H_{p}(t)+C_{L}(t) \times L_{p}(t)+W(t) \times O_{p}(t) \\
& +C_{O}(t) \times O H_{p}(t)+C_{M S}(t) \times I M_{p}(t)+C_{S U}(t) \times S_{p}(t)-\forall p, t
\end{aligned}
$$

$$
\text { Inventories balance: } \begin{aligned}
& I p(t-1)-B_{p}(t-1)+P_{p}(t)=I_{p}(t)-B_{p}(t)+F_{p}(t) \quad \forall p, t \\
& I M_{p}(t-1)+S_{p}(t)=I M_{p}(t)+P_{p}(t) \quad \forall p, t
\end{aligned}
$$

Material availability: $P_{p}(t) \leq I M_{p}(t-1) \quad \forall p, \forall t$

Number of operators balance: $O_{p}(t-1)+H_{p}(t)=L_{p}(t)+O_{p}(t) \quad \forall p, t$ 


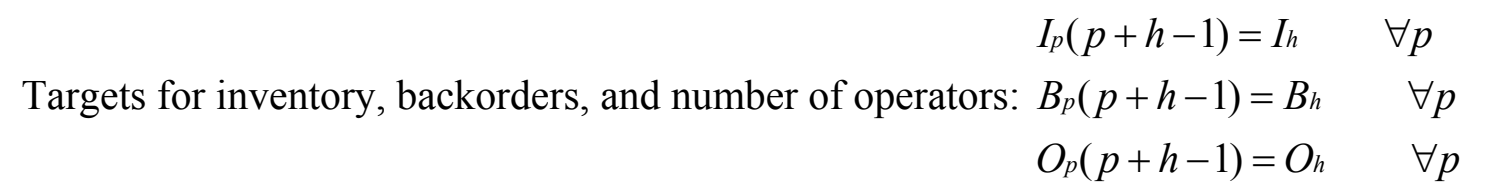

Resource constraint: $0 \leq P_{p}(t) \leq C R(t) \quad \forall p, t \quad$ (6)

Labour constraint: $0 \leq P_{p}(t) \leq u(t) \times O_{p}(t)+u o(t) \times O H_{p}(t) \quad \forall p, t$

Storage constraint: $0 \leq I_{p}(t)+I M_{p}(t) \leq C S(t) \quad \forall p, t$

Overtime constraint: $0 \leq O H_{p}(t) \leq C O(t) \times O_{p}(t) \quad \forall p, t \quad(9)$

Positive variables: $0 \leq O_{p}(t), H_{p}(t), L_{p}(t), B_{p}(t), P_{p}(t), S_{p}(t), O H_{p}(t) \quad \forall p, t$

Equation (3) assumes that one unit of product consumes one unit of raw material. Also it introduces one period lead-time between supply and consumption of raw material: production in period $t$ is constrained by raw material put in stock in period $t-1$. These two hypotheses can easily be changed depending on the industrial context.

In the first policy, the costs induced by cancellations or additional purchases are not taken into account when elaborating the plan, but are calculated as a result of the decision in order to compare the two policies.

\section{d) Linear Model with reference plan}

To model this policy, the following notations are introduced:

$\mathrm{C}_{\mathrm{EX}}(\mathrm{t})$ : overcost per additional raw material unit purchased compared to the reference plan,

$\mathrm{C}_{\mathrm{CA}}(\mathrm{t})$ : overcost per raw material unit cancelled compared to the reference plan,

$\mathrm{EX}_{\mathrm{p}}(\mathrm{t})$ : number of raw material units supplied in addition to the quantity of reference in period t planned in period $\mathrm{p}$,

$\mathrm{CA}_{\mathrm{p}}(\mathrm{t})$ : number of raw material units cancelled in period $\mathrm{t}$ planned in period $\mathrm{p}$ $\mathrm{EX}_{\mathrm{p}}(\mathrm{t})$ and $\mathrm{CA}_{\mathrm{p}}(\mathrm{t})$ represent the difference to the reference plan. A variation exists if one of these variables is positive. These additional variables are determined by optimisation of the 
model. This optimisation consists of providing a compromise between the stability $(\mathrm{EXp}(\mathrm{t})$ and CAp(t) are null) and the delay costs.

The planning objective remains the same: to minimize the costs on the planning horizon. Now, the costs induced by cancellation or additional purchases are taken into account when elaborating the plan. They represent weightings, i.e. the manager aversion to carry out these modifications.

The optimised cost function becomes:

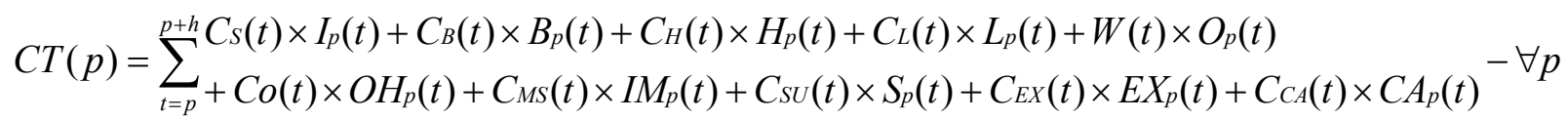

It is optimised under constraints of the equations (2)-(10) and (12)-(13).

Raw material balance: $I M_{p}(t)=I M_{p-1}(t)-C A_{p}(t)+E X_{p}(t) \quad \forall p, t$

Positive variables: $0 \leq E X_{p}(t), C A_{p}(t) \quad \forall p, t$

\section{e) Indicators}

The real costs generated on the $\mathrm{n}$ simulated periods are obviously monitored. The robustness is described by the standard deviation of the induced costs. This indicator allows one to observe the variability of the measured function.

The service performance, $\mathrm{I}_{\mathrm{SP}}$, is the average over $\mathrm{n}$ simulated periods of the quantity delivered divided by the quantity to be delivered, $\mathrm{I}_{\mathrm{pSP}}$. The quantity to be delivered is the backorders of the previous period plus the demand of the period.

if $I_{p}(t) \geq 0$ then $I_{p S P}=1 \forall p$

if $I_{p}(t)<0$ then $I_{p S P}=\frac{B_{p-1}(t)+D_{p}-B_{p}(t)}{B_{p-1}(t)+D_{p}} \forall p$ 
In our case, the measured instability, $\mathrm{I}_{\mathrm{s}}$, relates to the volume supplied over each period. This indicator is different from that of De Kok and Inderfurth (1997) or of Kimms (1998). It relates to the variation of volume between the forecast of period $t+1$ decided in $t$, and the quantity actually supplied in $\mathrm{t}+1$ period.

\section{f) Values and costs used}

\begin{tabular}{|c|c|c|c|c|c|c|c|c|c|c|c|c|}
\hline & 1 & 2 & 3 & 4 & 5 & 6 & 7 & 8 & 9 & 10 & 11 & 12 \\
\hline Holding costs & 20 & 20 & 20 & 20 & 20 & 20 & 20 & 20 & 20 & 20 & 20 & 20 \\
\hline Backorders costs & 60 & 60 & 60 & 60 & 60 & 60 & 60 & 60 & 60 & 60 & 60 & 60 \\
\hline Hiring costs & 400 & 400 & 400 & 400 & 400 & 400 & 400 & 400 & 400 & 400 & 400 & 400 \\
\hline Layoff costs & 500 & 500 & 500 & 500 & 500 & 500 & 500 & 500 & 500 & 500 & 500 & 500 \\
\hline Regular Wages & 1600 & 1600 & 1600 & 1600 & 1600 & 1600 & 1600 & 1600 & 1600 & 1600 & 1600 & 1600 \\
\hline Overtime costs & 15 & 15 & 15 & 15 & 15 & 15 & 15 & 15 & 15 & 15 & 15 & 15 \\
\hline Supply costs & 200 & 200 & 200 & 200 & 200 & 200 & 200 & 200 & 200 & 200 & 200 & 200 \\
\hline Material holding costs & 10 & 10 & 10 & 10 & 10 & 10 & 10 & 10 & 10 & 10 & 10 & 10 \\
\hline Qty. cancel cost & 60 & 30 & 0 & 0 & 0 & 0 & 0 & 0 & 0 & 0 & 0 & 0 \\
\hline Qty. Express supply costs & 60 & 30 & 0 & 0 & 0 & 0 & 0 & 0 & 0 & 0 & 0 & 0 \\
\hline
\end{tabular}

Table 2: costs of decision variables

$\mathrm{n}=12 \mathrm{~h}=12$

$\alpha=0.3$

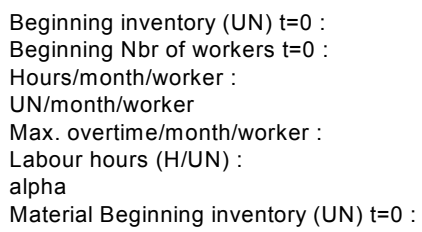

\begin{tabular}{|r|}
\hline 0 \\
5 \\
160 \\
8 \\
20 \\
20 \\
0.3 \\
0 \\
\hline
\end{tabular}

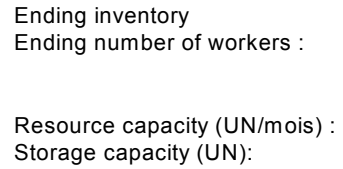

Table 3: constraints parameters

As mentioned previously, controllable factors exist for a tactical plan (Thomas and Lamouri, 2000). By using an experimental design, these controllable factors can be fixed at levels which make it possible to minimize the total cost of the plan. In this article, the values of these factors are fixed to levels found in Thomas and Lamouri (2000).

\section{Simulation}

Simulation is an approach which reproduces the dynamic behaviour of the decision-making model. To examine the dynamic nature of the supply chain, an approach using a rolling horizon is adopted. That means that as time increases, new information becomes available (the current demand and new forecasts), and the decision variables and performance indicators are re-valued. 
The current demand follows a normal distribution with a mean equal to the forecast and a standard deviation equal to 6 . The forecasts established for the following periods are recomputed by taking into account the current demand according to an exponential model with a coefficient $\alpha$. The initial forecasts $F_{o}(t)$ are represented on figure 2 .

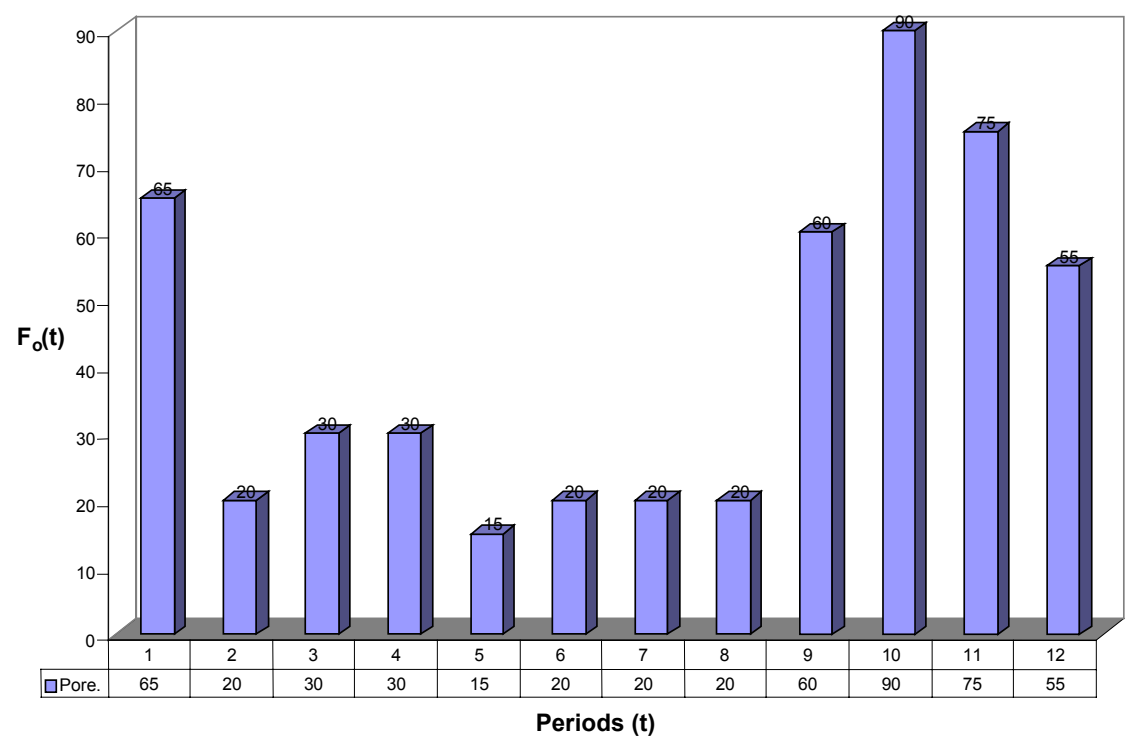

Figure 2: Initial Forecasts $\mathrm{p}=0$

10 '000 simulations were carried out for each of the two cases, with or without a reference plan, according to the values indicated previously. Values were held constant for both cases. At each period, the model is optimised according to the calculated forecasts. It gives the tactical plan from which the first period is implemented: production, overtime, hiring are executed and raw material forecasts are transmitted. Then, the current demand is introduced making it possible to calculate the real costs for the period. New forecasts are then given, and the index is incremented (Figure 3). 


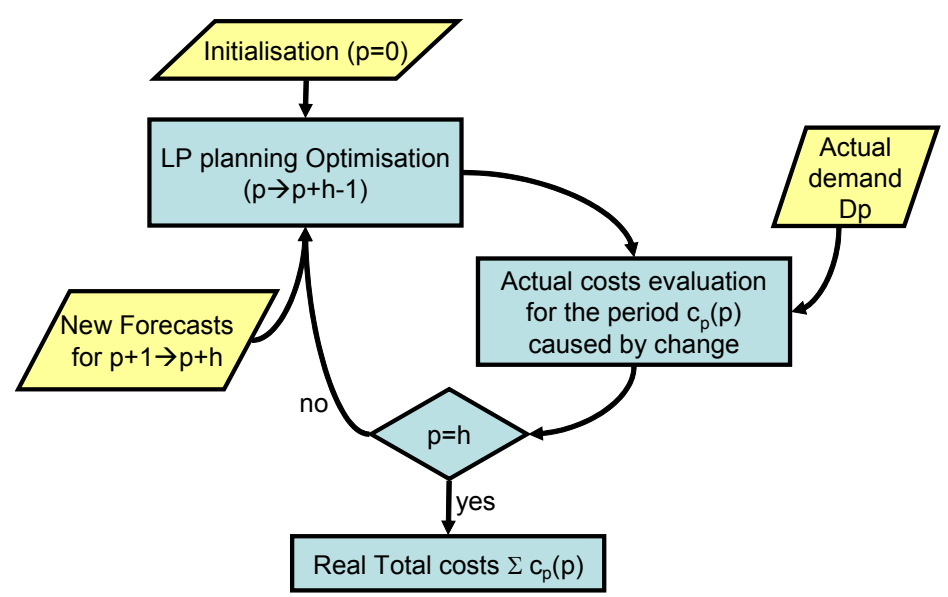

Figure 3: Simulation process with the basic model

In the case of simulation with a "reference plan", the plan of the period is preserved in order to be used as the input for the model optimised in the following period (Figure 4).

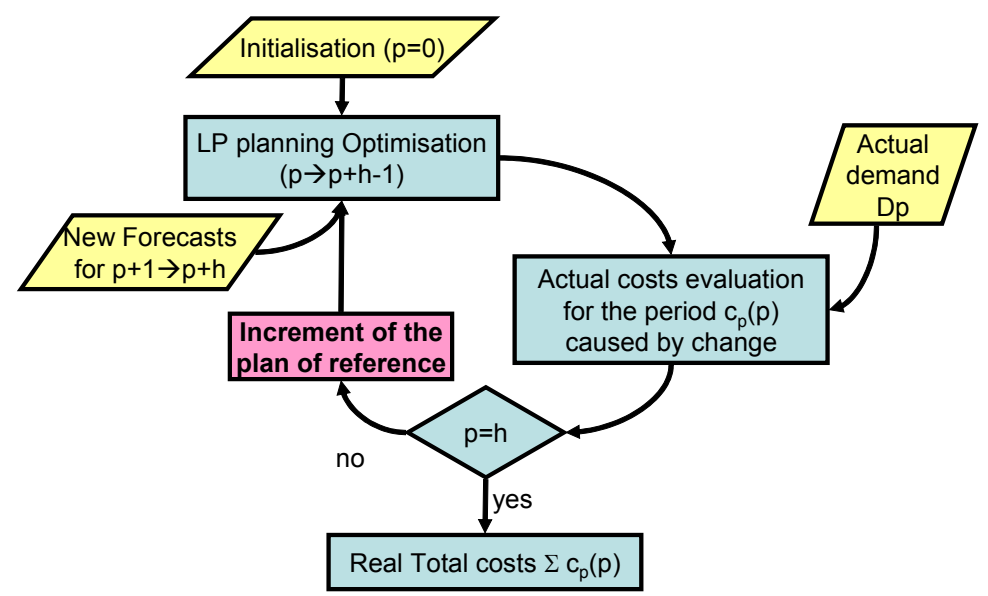

Figure 4: Simulation process with reference plan model

At each period, the indicators are incremented.

The only parameters that change from one simulation to another, is the set of demands and forecasts. However, the same sets are used for each policy. Therefore, only the processes used to establish the tactical plan changes from one case to the other.

The difference between the two processes is in the way the costs of a change in variables enclosed within the reference plan are taken into account. In the process with a reference plan, costs of change are clearly evaluated in the decision-making procedure. For the other process, they are evaluated after the decision-making. 


\section{Results}

We are comparing two different processes of establishing a tactical plan and highlight their impacts on several indicators. Figure 5 resumes the impact of each process on each indicator.

\begin{tabular}{|l|c|c|}
\hline \multicolumn{1}{|c|}{ Indicators } & Without Reference plan & With reference plan \\
\hline Costs & 235000 & $\begin{array}{c}228000 \\
\text { (decrease) }\end{array}$ \\
\hline Robustness & 13790 & $\begin{array}{c}12860 \\
\text { (increase) }\end{array}$ \\
\hline $\begin{array}{l}\text { Customer } \\
\text { service }\end{array}$ & $62 \%$ & $\begin{array}{c}71 \% \\
\text { (increase) }\end{array}$ \\
\hline Stability & 11 & $\begin{array}{c}3 \\
\text { (increase) }\end{array}$ \\
\hline
\end{tabular}

Figure 5: Indicators comparison

The first graph (Figure 6) represents the number of simulations with the same range of annual costs. Each curve represents one of the processes.

The first notable result is that a strategy of planning with a reference plan reduces annual costs, while improving the robustness in costs. Indeed, the standard deviation for this strategy is smaller.

As in our experimental method, the only factor that changes is the process to elaborate a tactical plan, we conclude here that this factor influences the robustness of tactical planning. 


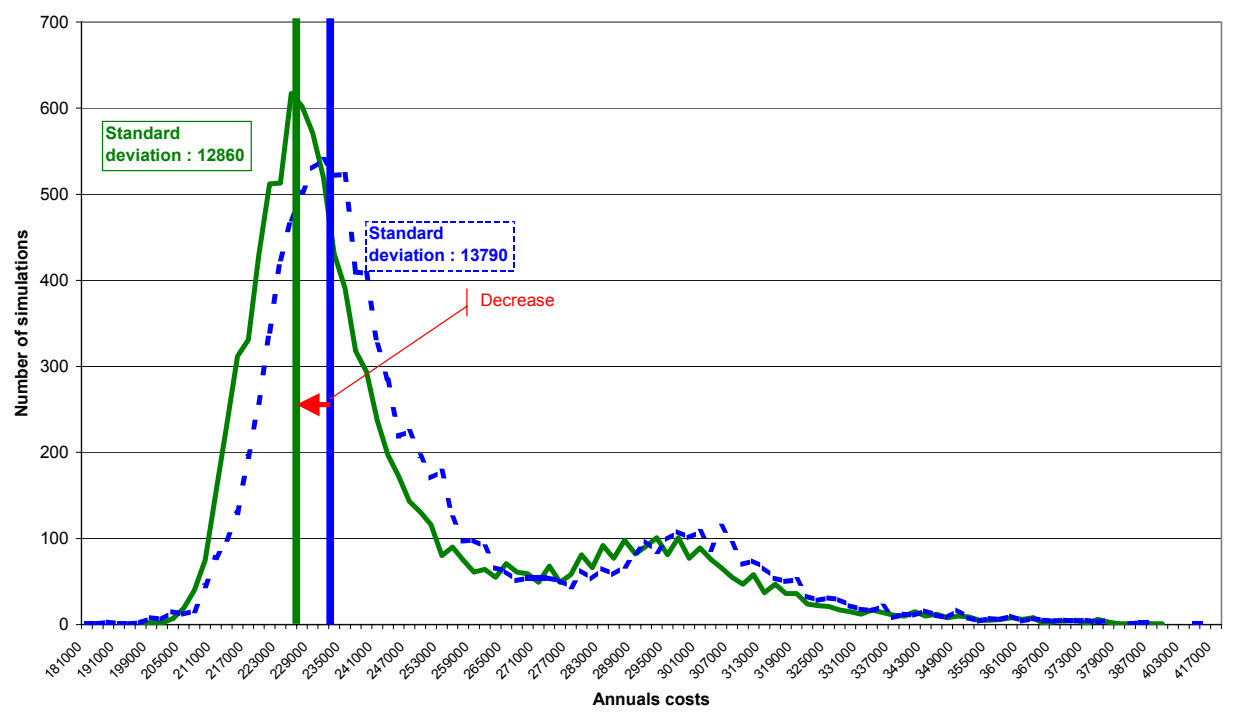

with plan of ref. - - Without plan of ref.

\begin{tabular}{|c|c|c|c|c|c|c|c|c|}
\hline $\begin{array}{l}\text { Annuals } \\
\text { costs }\end{array}$ & Whitout Plan & With plan & $\begin{array}{l}\text { Annuals } \\
\text { costs }\end{array}$ & Whitout Plan & With plan & $\begin{array}{c}\text { Annuals } \\
\text { costs }\end{array}$ & Whitout Plan & With plan \\
\hline 181000 & & 1 & 257000 & 75 & 97 & 327000 & d 17 & 29 \\
\hline 185000 & 0 & 1 & 259000 & 61 & 98 & 329000 & 15 & 22 \\
\hline 189000 & 0 & 3 & 261000 & 64 & 90 & 331000 & 12 & 18 \\
\hline 191000 & 0 & 1 & 263000 & 55 & 66 & 333000 & 17 & 16 \\
\hline 195000 & 0 & 1 & 265000 & 71 & 62 & 335000 & 14 & 21 \\
\hline 197000 & 3 & 2 & 267000 & 61 & 51 & 337000 & 11 & \\
\hline 199000 & 2 & 8 & 269000 & 59 & 54 & 339000 & 10 & 12 \\
\hline 201000 & 2 & 6 & 271000 & 49 & 54 & 341000 & 15 & 11 \\
\hline 203000 & 7 & 15 & 273000 & 68 & 54 & 343000 & $\frac{\pi}{10}$ & 16 \\
\hline 205000 & 19 & 12 & 275000 & 49 & 51 & 345000 & 12 & 11 \\
\hline 207000 & 40 & 16 & 277000 & 58 & 44 & 347000 & 8 & 8 \\
\hline 209000 & 75 & $\frac{15}{45}$ & 279000 & 81 & $\frac{74}{63}$ & 349000 & $\frac{0}{10}$ & 17 \\
\hline 211000 & 153 & 78 & 281000 & 66 & 53 & 351000 & 9 & 8 \\
\hline 213000 & 231 & 99 & 283000 & 92 & 65 & 353000 & 5 & $\frac{4}{4}$ \\
\hline 215000 & 312 & 130 & 285000 & 77 & 58 & 355000 & 5 & \\
\hline 217000 & 331 & 195 & 287000 & 98 & 68 & 357000 & 6 & 6 \\
\hline 219000 & 429 & 258 & 289000 & 82 & 84 & 359000 & 8 & 10 \\
\hline 221000 & 512 & 341 & 291000 & 91 & 97 & 361000 & 6 & \\
\hline 223000 & 513 & 425 & 293000 & 101 & 85 & 363000 & 8 & \\
\hline 225000 & 617 & 471 & 295000 & 81 & 99 & 365000 & 1 & 5 \\
\hline 227000 & 602 & 502 & 297000 & 101 & 108 & 367000 & 4 & $\frac{4}{4}$ \\
\hline 229000 & 571 & 530 & 299000 & 77 & 101 & 369000 & & \\
\hline 231000 & 520 & 540 & 301000 & 89 & 108 & 371000 & 5 & \\
\hline 233000 & 431 & 522 & 303000 & 76 & 87 & 373000 & 1 & 5 \\
\hline 235000 & 391 & 523 & 305000 & 66 & 114 & 375000 & 6 & 3 \\
\hline 237000 & 318 & 410 & 307000 & 55 & 94 & 377000 & & \\
\hline 239000 & 294 & 408 & 309000 & 47 & 70 & 379000 & & \\
\hline 241000 & 237 & 325 & 311000 & 58 & 74 & 381000 & 1 & \\
\hline 243000 & 197 & 284 & 313000 & 37 & 66 & 385000 & 2 & 2 \\
\hline 245000 & 172 & 219 & 315000 & 47 & 54 & 387000 & & \\
\hline 247000 & 143 & 224 & 317000 & $\frac{41}{36}$ & 50 & 391000 & 1 & 0 \\
\hline 249000 & $\frac{131}{131}$ & 196 & 319000 & 36 & 52 & 401000 & 0 & \\
\hline 251000 & 116 & 170 & $\frac{321000}{32}$ & 24 & 33 & 403000 & 1 & 0 \\
\hline 253000 & 80 & 178 & 323000 & 22 & 28 & 409000 & d & \\
\hline 255000 & 90 & 124 & 325000 & 21 & 31 & 411000 & वे & \\
\hline
\end{tabular}

Figure 6: annual costs variability 


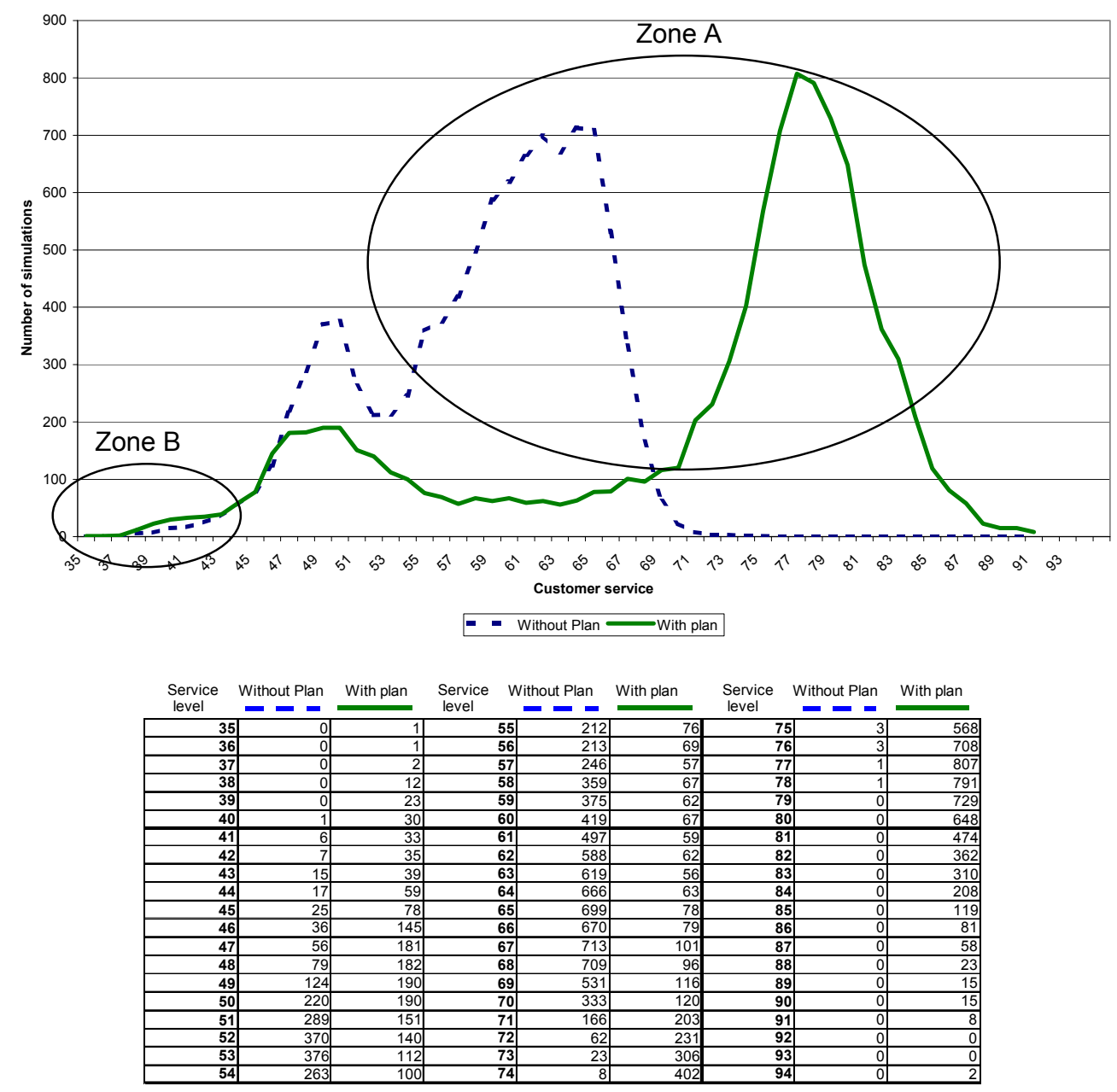

Figure 7: Customer service indicator

The $\mathrm{I}_{\mathrm{SP}}$ indicator, or service performance, shows a strong difference between the two strategies (Figure 7). The strategy with a reference plan lead to an increase of more than $10 \%$ in service performance with the data set used (Zone A). This result is obtained by a strategic buffer of raw materials (Figure 8). Indeed, the model supports additional raw material inventory even if it means high storage costs. It makes it possible to react more quickly to unforeseen demand without risking costs of change. A service level around $80 \%$ can appear low compared to current standards. The data file makes the simulation begin with a null stock in the period of high demand. The initial conditions thus impose a degraded service level. Further work must be done to analyse the impact of initial conditions on robustness of the plan. 


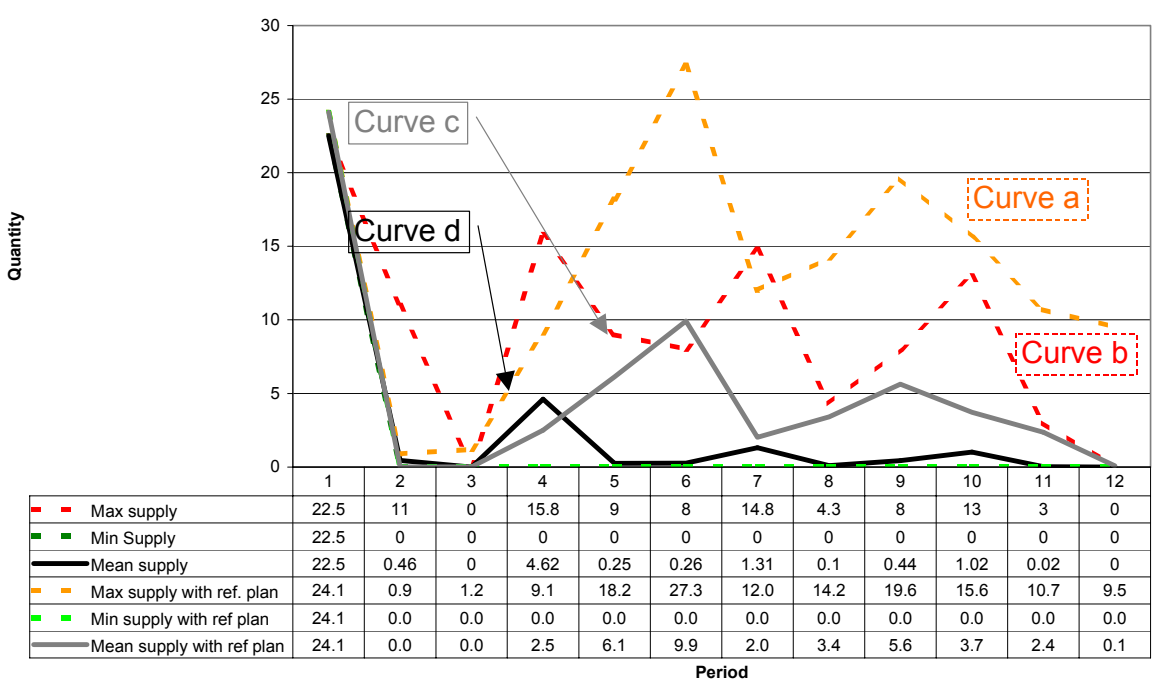

Figure 8: Raw material inventory level at the end of each period

The curve "c" represents the average level of raw material inventory over all the scenarios for periods with a reference plan. The curve "d" represents that obtained without a reference plan. Figure 8 shows that this inventory is, on average, higher with a reference plan. The same conclusion is obtained when the maximum raw material inventory is analysed. Curve "a" represents the maximum inventory generated on all the simulations using the model with a reference plan. Curve " $b$ " represents the same data for the other case. The first curve is higher than the second. If the storage costs are higher than the costs of change, or if demand is decreasing, the model reacts as in the basic case.

We also found that the model with reference plan generates some cases of a bad service performance (Figure 7, Zone B). The model chooses in these cases stability by keeping the quantity of raw material to be supplied unchanged, and thus degrades the service performance by limiting the production.

With regard to the indicator of stability, $\mathrm{I}_{\mathrm{S}}$, the profit of a strategic "reference plan" is obvious. Figure 9 represents the number of simulations according to the number of changes in the supplied quantities of raw materials. From permanent modifications, a quasi stability 
is reached. It should be noted, however, that the model allows for changes when the difference is too large. With this kind of model, a degree of freedom is conserved. This is not possible with the frozen time fences used traditionally to reduce nervousness (Vollman et al., 1997).

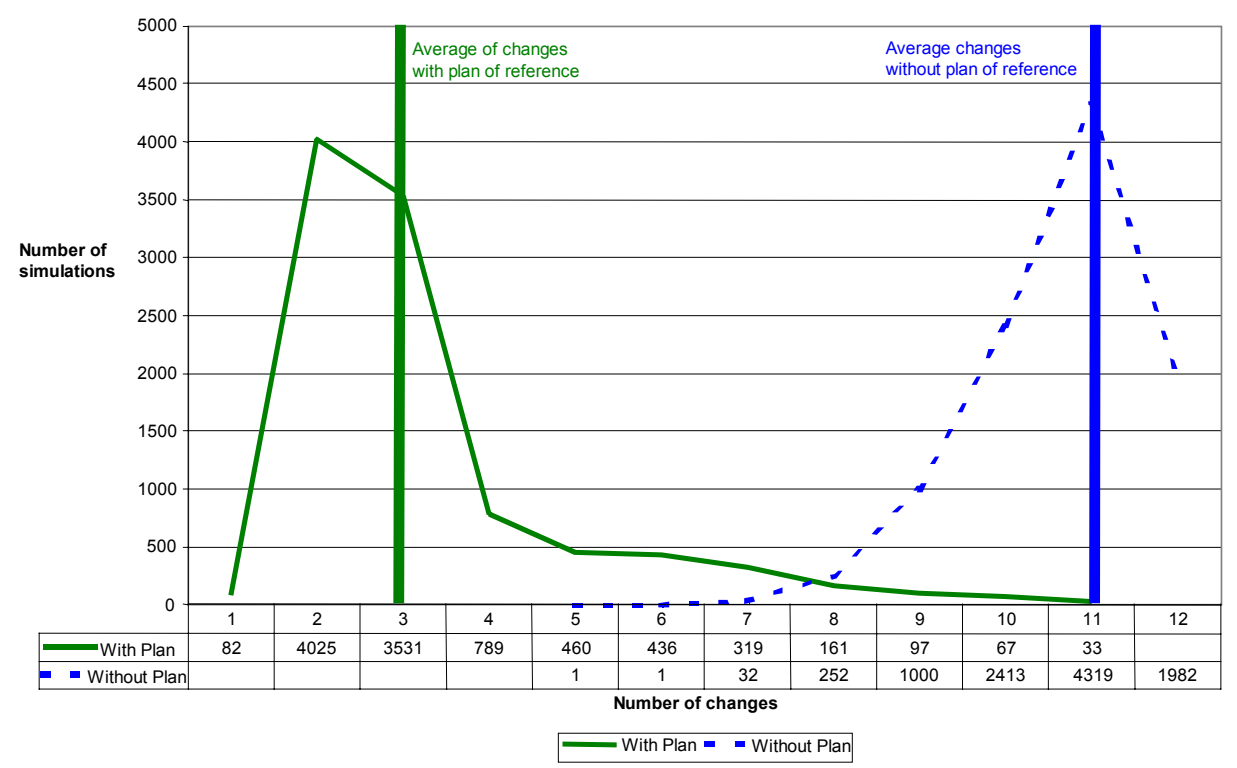

Figure 9: distribution of the number of changes in supplied quantities

\section{Conclusions}

In this article, we have analysed the influence of the tactical planning process on robustness and stability. We have also proposed an approach to reduce planning nervousness while allowing a certain level of reactivity. Establishment of tactical planning uses a reference plan from the previous cycle as a constraint during the re-optimisation of the model. A limited number of modifications can be done this way, according to the horizon, thus making it possible to ensure stability in supply while improving the robustness in costs.

Always based on linear or mixed-integer programming, this planning logic can be implemented in an APS by adapting the models already employed. 
Being a promising approach, future work includes more extreme cases treated by experimental design in order to analyse the impact of controllable factors as the standard deviation of the demand $(\alpha)$, the holding costs, the delays cost, the modifications and the demand pattern. It will also have to be adapted to other decisional situations modelled in APS.

However, it should be noted that in many cases the impact of plan instability cannot be evaluated by costs. Indeed, the "costs" associated with re-planning depend on the level on flexibility in capacities at various horizons. They also depend on the modifications of production in the short-term, which are induced by re-planning processes. Moreover, the loss of confidence in the planning system or in the supply chain department cannot be easily expressed financially. Thus, the suggested approach appears to have the potential for considerable benefit, if not always easy to evaluate financially. It is, however, necessary to study the impact of these changes to current practices, for example:

- $\quad$ on the variability of demand on a supplier which is an external capacity constraint,

- on confidence in the case of annual contracts,

- $\quad$ on the utilisation rate of the related departments (warehousing, purchasing, ...)

Other approaches to reduce planning nervousness can be adapted to our situation by modifying the model. They do not use the concepts of cost. In particular, fuzzy logic computes robustness and "smoothed" plan changes under constraints. Future work will apply this method to the tactical planning model discussed in this article.

\section{Bibliography}

Beale E.M.L., 1955. On minimizing a convex function subject to linear inequalities, Journal of Royal Statistics Society 17 173-184.

Blackburn J.D., Kropp H.D., Millen R.A., 1986. Comparison of strategies to dampen nervousness in MRP systems, Management Science 32 (4) 413-429. 
Carlson R.C., Beckman S.L., Kropp D.H., 1982. The electiveness of extending the horizon in rolling production schedules, Decision Sciences 13 (1) 129-146.

Christopher M., 1992. Logistics and Supply Chain Management, Financial Times, Pitman, London.

Dantzig G.B., 1955. Linear programming under uncertainty, Management Science 1 197-206.

Disney S.M., Towill D.R., 2003. The effect of vendor managed inventory (VMI) dynamics on the Bullwhip Effect in Supply Chains, International Journal of Production Economics 199-215.

Donselaar K.H.V., Nieuwenhof J.V.D., Visschers J., 2000. The impact of material coordination concepts on planning stability in supply chains, International Journal of Production Economics 68 169-176.

Forrester J, 1958. Industrial Dynamics, A major breakthrough for decision makers, Harvard Business Review, July August 67-96.

Graves S.C., Rinnooy Kan A.H.G., Zipkin P.H., 1993. Logistics of Production and Inventory, NorthHolland, Amsterdam.

Heisig G., 1998. Planning stability under (s, S) inventory control rules, OR Spektrum 20 (4) 215-228.

Ho C., 1989. Evaluating the impact of operating environments on MRP system nervousness, International Journal of Production Research 27 1115-1135.

Holmström J., 1997. Product range study of supply chain operations in the European grocery industry, Supply Chain Management 2 (3) 107-115.

Jensen T., 1993. Measuring and improving planning stability of reorder point lot-sizing policies, International Journal of Production Economics 30-31 167-178.

Johnson L.A., Montgomery D.C., 1974. Operations research in production planning, Scheduling and Inventory Control, Wiley, New York.

Kadipasaoglu S.N., Sridharan V., 1995. Alternative approaches for reducing schedule instability in multi-stage manufacturing under demand uncertainty, Journal of Operations Management 13 193-211.

Kimms A., 1998. Stability measures for rolling schedules with applications to capacity expansion planning, master production scheduling, and lot sizing, International Journal of Management Science 26 (3) 355-366.

Kleijnen J.P.C., Gaury E., 2003. Short-term robustness of production management systems: A case study, European Journal of Operational Research 148 452-465.

De Kok A.G., Inderfurth K., 1997. Nervousness in inventory management: comparison of basic control rules", European Journal of Operational Research 103 55-82.

Koltai T., Terlaky T., 2000. The difference between the managerial and mathematical interpretation of sensitivity analysis results in linear programming, International Journal of Production Economics 65 257-274.

Lee H.L., Billington C., 1995. The evolution of supply-chain-integration models in practice at Hewlett-Packard, Interfaces 25 (5) 42-63.

Lee J. H., Yu Z. H., 1997. Worst-case formulations of model predictive control for systems with bounded parameters, Automatica 33 765-781.

Minifie J.R., Davis R.A., 1990. Interaction effects on MRP nervousness, International Journal of Production Research 28 173-183.

Mulvey J.M., Vanderbei R.J., Zeinios S.A., 1995. Robust optimization of large-scale systems, Operations Research 43 (2) 264-281. 
Orlicky J., 1975. Material Requirements Planning, McGraw-Hill, London.

Rota K., Thierry C., Bel G., 2002. Supply Chain Management: a supplier perspective, Production Planning and Control 370-380.

Simampo A., Ryan S.M., 2003. Capacity expansion for a loss system with exponential demand growth, Computers and Operations Research 1525-1537.

Simchi-Levi D., Kaminsky P., Simchi-Levi E., 2000. Designing and Managing the Supply Chain, Irwin, Homewood/McGraw-Hill, Boston.

Sridharan S.V., Laforge R.L., 1990. An analysis of alternative policies to achieve schedule stability, Journal of Manufacturing and Operations Management 3 53-73.

Stadtler H., Kilger C., 2000. Supply chain Management and Advanced Planning: concepts, Models, Software and case studies, Springer.

Taguchi G., 1987. Orthogonal arrays and linear graph, American Supplier Institute press.

Thomas D.J., Griffin P.M., 1996. Coordinated supply chain management, European Journal of Operational Research 94 1-15.

Thomas A., Lamouri S., 2000. The new problem with Sales, Inventories and Operations planning in a Supply Chain environment, Proceedings RB08, Boston.

Vollman T.E., Berry W.L., Whybark D.C., 1997. Manufacturing planning and control systems, 4th ed., New York et al.

Yano C.A., Carlson R.C., 1987. Interaction between frequency of rescheduling and the role of safety stock in material requirements planning systems, International Journal of Production Research 25 221-232.

Yu C.-S., Li H.-L., 2000. A robust optimization model for stochastic logistic problems, International Journal of Production Economics 64 385-397.

Zhao X., Lee T.S., 1993. Freezing the master production schedule for material requirements planning systems under demand uncertainty, Journal of Operations Management 11 (2) 185-205.

Zhao X., Xie J., Leung J., 2002. The impact of forecasting model selection on the value of information sharing in a supply chain, European Journal of Operation Research 321-344. 